\title{
Epidemiologia e controle dos focos da doença de Aujeszky no Rio Grande do Sul, em $2003^{1}$
}

\author{
Fernando H. Sauter Groff ${ }^{2,3}$, Maria A. Merlo³, Pedro A. Stoll ${ }^{3}$, Ana Lúcia Stepan ${ }^{4}$, \\ Rudi Weiblen ${ }^{5}$ e Eduardo F. Flores ${ }^{6 *}$
}

\begin{abstract}
GroffF.H.S., Merlo M.A., Stoll P.A., Stepan A.L., Weiblen R. \& Flores E.F. 2005. [Epidemiology and control of pseudorabies outbreaks in the state of Rio Grande do Sul, Brazil, 2003.] Epidemiologia e controle dos focos da doença de Aujeszky no Rio Grande do Sul, em 2003. Pesquisa Veterinária Brasileira 25(1):25-30. Depto Medicina Veterinária Preventiva, Universidade Federal de Santa Maria (UFSM), Santa Maria, RS 97105-900, Brazil. E-mail: flores@ccr.ufsm.br

Aujeszky's disease (AD) or pseudorabies is an important viral disease of swine and has significant economic impact on the pig industry worldwide. The infection produces direct and indirect economic losses, mainly due to restrictions to international trade of swine products. Since the beginning of the 20th century, $\mathrm{AD}$ had been notified in several Brazilian regions, yet the state of Rio Grande do Sul (RS) remained as a "provisionally free" area under the International Organization of Epizooties (OIE) guidelines. In 2003, two outbreaks were notified in swine herds located in northern RS, boundary with Santa Catarina, a state where the infection is endemic. Control/eradication measures consisted in tracing back all swine movements, quarantine and eradication of the affected herds by sanitary slaughter under official inspection. In outbreak \# 1 (Pinheirinho do Vale, January/ 2003) six herds were affected, one of which presented animals with clinical signs. Starting from this outbreak, 146 herds and 42.399 pigs were traced back, six herds ( 7.822 animals) being depopulated - the herd where the index outbreak plus five other herds with positive serology. The outbreak \# 2 (Aratiba, September/2003) resulted in a wider spread of the infection, involving another three counties and 77 herds ( 9 with clinical signs, 68 with positive serology). From the index case, 109.316 pigs in 630 herds were traced back; 28.443 animals from positive herds were slaughtered. Total numbers reached 151.715 traced back animals in 776 herds; 71 herds were found serologically positive. The adopted measures were efficient to eliminate the outbreaks and to stop the disease spread to neighboring areas, reestablishing the sanitary status previous to the outbreaks
\end{abstract}

INDEX TERMS: Aujeszky's disease, pseudorabies, ADV, PRV, epidemiology.

RESUMO.- A doença de Aujeszky (DA), ou pseudo-raiva, é uma enfermidade infecto-contagiosa de etiologia viral de grande importância para a suinocultura comercial em todo o mundo. A infecção causa perdas econômicas diretas e indiretas, pela res-

\footnotetext{
${ }^{1}$ Recebido em 9 de dezembro de 2004.

Aceito para publicação em 21 de fevereiro de 2005.

2 Programa de Pós-Graduação em Medicina Veterinária da Universidade Federal de Santa Maria (UFSM).

${ }^{3}$ Divisão de Fiscalização e Defesa Sanitária Animal (DFDSA/DPA/SAA/RS).

${ }^{4}$ Fiscal Federal Agropecuário (DDA/MAPA/RS).

${ }^{5}$ Departamento de Medicina Veterinária Preventiva, Centro de Ciências Rurais, UFSM.

${ }^{6}$ Departamento de Medicina Veterinária Preventiva, Centro de Ciências Rurais, UFSM, Santa Maria, RS 97105-900, Brasil. *Autor para correspondência. E-mail: flores@ccr.ufsm.br
}

trição ao comércio internacional de produtos suínos. Embora a DA venha sendo notificada em várias regiões do Brasil desde o início do século XX, o Rio Grande do Sul (RS) permanecia "provisoriamente livre" com base em critérios da Organização Internacional de Epizootias (OIE). Em 2003 ocorreram dois focos da enfermidade em municípios do norte do RS, limítrofes com Santa Catarina, Estado que tem registrado vários focos nos últimos anos. Como estratégia de combate foram determinados o rastreamento da movimentação de suínos, a interdição da área e a erradicação dos focos através de abate sanitário em matadouros sob Inspeção Federal. No evento 1 (Pinheirinho do Vale, janeiro de 2003) cinco unidades produtoras de leitões (UPLs) foram afetadas, sendo que uma apresentou animais com sinais clínicos. A partir desse foco foram rastreados 42.399 suínos em 146 rebanhos, sendo eliminados seis rebanhos - o foco índice e cinco outras com sorologia positiva - num total de 7.822 ani- 
mais. No evento 2 (Aratiba, setembro de 2003), a disseminação da infecção foi maior, atingindo outros três municípios e 77 granjas (nove com sinais clínicos, 68 com sorologia positiva). Foram rastreados 109.316 suínos em 630 rebanhos, com a erradicação de 28.443 animais das granjas que apresentaram sinais clínicos ou sorologia positiva. No total foram rastreados 151.715 animais em 776 rebanhos, sendo detectados 71 rebanhos com sorologia positiva. Essas medidas foram eficazes na erradicação dos focos e impediram a disseminação da enfermidade para outras regiões, permitindo ao RS readquirir o status sanitário anterior aos surtos.

TERMOS DE INDEXAÇÃO: Doença de Aujeszky, pseudo-raiva, VDA, PRV, epidemiologia.

\section{INTRODUÇÃO}

A doença de Aujeszky (DA) ou pseudo-raiva é uma enfermidade infecto-contagiosa de etiologia viral que se constitui em um importante obstáculo à exploração e ao comércio internacional de suínos em todo o mundo. A etiologia da doença foi determinada no início do século XX (Kluge et al. 1999) e a primeira notificação no Brasil ocorreu em 1932 (Vidor 1988). A DA é uma enfermidade de importância sanitária e econômica estratégica na suinocultura e é enfermidade de notificação anual obrigatória (OIE 2003).

$\mathrm{O}$ agente etiológico da DA é o herpesvírus suíno tipo 1 , ou vírus da Doença de Aujeszky (VDA), classificado na família Herpesviridae, subfamília Alphaherpesvirinae, gênero Varicellovirus (Roizman \& Pellet 2001). Os hospedeiros primários do VDA são os suínos domésticos e silvestres, embora o vírus possa infectar outras espécies de mamíferos domésticos, entre os quais gatos, cães e bovinos. Nessas espécies, o vírus produz encefalite de curso agudo fatal, o que reduz a importância epidemiológica desses hospedeiros na manutenção e disseminação da enfermidade (Crandell et al. 1982, Kluge et al. 1999, Sobestiansky et al. 1999). A ocorrência da doença nessas espécies, no entanto, pode servir como indicador epidemiológico da presença de atividade viral.

A propriedade biológica de maior importância epidemiológica do VDA é a capacidade de estabelecer infecções latentes no sistema nervoso do hospedeiro após a infecção aguda. A infecção latente persiste por toda a vida do animal, podendo ser reativada natural e/ou experimentalmente, resultando em excreção e transmissão de vírus. Por isso, os animais soropositivos constituem-se em reservatórios e fontes potenciais de disseminação do VDA (Kluge et al. 1999, Roizman \& Pellet 2001).

Os sinais clínicos da infecção pelo VDA variam de acordo com fatores epidemiológicos como endemicidade e suscetibilidade dos indivíduos. A ocorrência do VDA em áreas endêmicas é associada a manifestações reprodutivas. A introdução do vírus em rebanhos livres resulta em sinais clínicos característicos, que variam de acordo com a faixa etária. Em animais jovens predominam sinais neurológicos com a taxa de mortalidade aproximando-se dos $100 \%$. Animais adultos apresentam febre, taxas variáveis de aborto, reabsorção fetal, dificuldade respiratória e eventualmente vômitos. A mortalidade nessa faixa etária é geralmente baixa (Kluge et al. 1999, Sobestiansky et al. 1999).
Diferentes estratégias de combate têm sido preconizadas, dependendo da situação epidemiológica da DA em cada região. Alguns países onde a enfermidade é endêmica optaram por planos de erradicação a longo prazo, baseados no uso de vacinas com marcadores antigênicos e posterior teste/remoção de animais soropositivos (Kimman 1994, Morrison 1994, Van Oirschot 1996). Nesses casos, medidas de despopulação total de granjas demonstraram ser proibitivas economicamente (Rodrigues et al. 1990). Considerando diferentes situações de prevalência, concentração de rebanhos e presença do agente, esses programas são reavaliados periodicamente, para registrar progressos e eventualmente alterar estratégias e redirecionar recursos (Moynagh 1997, Vannier et al. 1997, Müller et al. 2003).

Entre 1996 e 2000 foram notificados vários focos de DA no Brasil, com a adoção de estratégias baseadas em vacinação e rastreamento de rebanhos. A depopulação total de granjas foi realizada apenas em alguns casos, por se tratar de área caracterizada como endêmica (OIE 2004). Não existe um programa oficial específico para controle da DA no Brasil, à exceção de Santa Catarina que implementou um programa com base no uso de vacinas com marcadores antigênicos e posterior teste/remoção dos animais infectados com vírus de campo (Mores \& Zanella 2003). Esse Estado tem registrado focos desde 1983 (Marques \& Romero 1986, Rowe \& Romero 1986), com aumento gradativo no número de granjas afetadas, com exceção do período de 2001 a 2003, quando houve uma redução no número de focos (Mores \& Zanella 2003). Nos demais Estados, a única exigência sanitária requerida é sorologia negativa para o VDA nas granjas de reprodutores suínos (MAPA 2002). O uso de vacinas é regulado por órgão oficial, e seu uso somente é permitido em situações de foco (MAPA 1985).

Os focos ocorridos no Rio Grande do Sul (RS) em 2003 constituem-se nos primeiros registros da enfermidade em suínos no Estado (Silva et al. 2003), pois a notificação original ocorreu em bovinos (Bauer 1955). A partir desse relato até 1996, não haviam sido detectadas evidências sorológicas da presença do agente no rebanho suíno do Estado (Roehe et al. 1996). A inexistência de notificações nesse período levou a OIE a classificar o Estado como "área provisoriamente livre", de acordo com o Código Zoosanitário Internacional (OIE 2003).

O objetivo deste trabalho foi descrever os aspectos epidemiológicos e os procedimentos utilizados na abordagem e erradicação dos focos ocorridos em 2003 no RS, analisando a origem e disseminação do agente nas áreas atingidas.

\section{MATERIAL E MÉTODOS}

Em janeiro e setembro de 2003 foram notificadas suspeitas clínicas de enfermidade compatível com DA em granjas do norte do RS. As estratégias adotadas nos dois eventos foram semelhantes, variando em algumas particularidades. Os diagnósticos foram confirmados através de isolamento viral e outras provas descritas no artigo subseqüiente (Silva et al. 2005).

A partir da confirmação etiológica, os procedimentos adotados seguiram a seguinte ordem:

1) Interdição da área: demarcação de raio de cinco quilômetros para movimentação de animais (OIE, 2003), com o auxílio de aparelhos de posicionamento global (GPS) através de coordenadas planas; 
2) Inquérito epidemiológico: inspeção das granjas por ordem de prioridade - a) granjas que haviam recebido suínos do foco índice/ primário; b) granjas vizinhas dos focos (dentro da área interditada); c) granjas com sinais compatíveis com DA dentro do sistema integrado. Um formulário de investigação epidemiológica adaptado para a situação (Dohon et al. 2003) foi utilizado em todas as granjas que abrigavam suínos naquele momento. Como parâmetro, foram pesquisados os 60 dias anteriores à confirmação do foco, sendo este período posteriormente ampliado para 90 dias;

3) Depopulação das granjas que apresentavam animais com sinais clínicos e isolamento viral positivo;

4) Sorologia: coleta e teste do soro de animais de todas as granjas inspecionadas que possuíam suínos, conforme tabela preconizada (MAPA 2002). No segundo evento foi realizada uma $2^{\text {a }}$ coleta em granjas de risco, definidas entre as que apresentaram resultados negativos na primeira amostragem e estavam inseridas nos parâmetros 'a' e 'c' de prioridade de inspeção;

5) Depopulação das granjas com animais soropositivos;

6) Vazio das instalações por 28 dias;

7) Desinfecções acompanhadas;

8) Vistoria final e liberação para repovoamento.

A estratégia de depopulação total foi adotada nos dois eventos, variando em algumas particularidades. Os dados gerados foram lançados em planilha do Microsoft Excel ${ }^{\circledR}$ elaborada com essa finalidade. As amostras de soros foram submetidas à prova de ELISA para triagem e de soro-neutralização (SN, titulação) para confirmação dos positivos, conforme preconizam normas internacionais (OIE 2000). Os dados da sorologia podem ser observados no Quadro 1.

\section{RESULTADOS}

\section{Evento 1 (E1)}

Notificado em 27.01.2003, inspecionado em 28.01.2003, com abertura de foco por uma equipe do Departamento de Produção Animal (DPA/SAA). O foco índice ocorreu em uma unidade produtora de leitões (UPL), localizada em Pinheirinho do Vale, noroeste do RS, divisa com Santa Catarina, em um núcleo de produtores de suínos pertencente a um sistema de integração, com 800 matrizes alojadas (Fig.1). Na área afetada foi observada uma alta concentração de rebanhos, alguns sem barreiras mínimas entre si. Foi observada alta mortalidade de leitões pré-des-

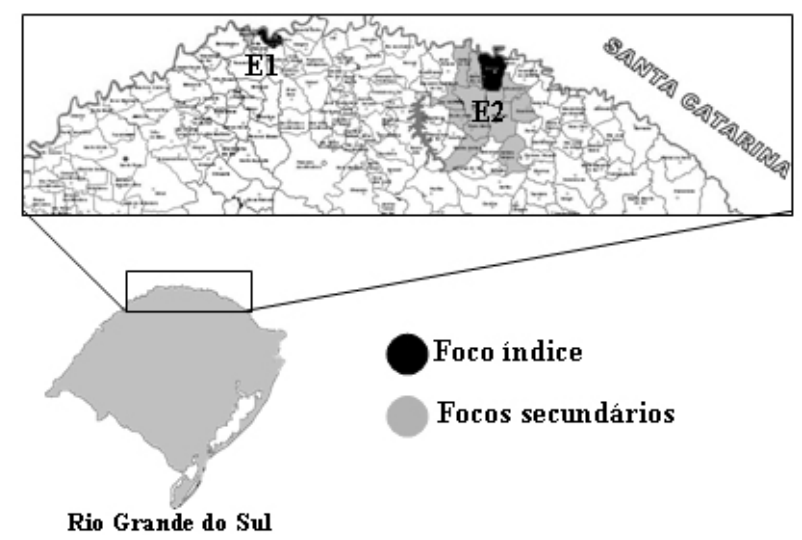

Fig.1. Mapa de localização dos municípios afetados pela doença de Aujeszky no Rio Grande do Sul em 2003. E1: dois municípios, E2, 11 municípios. mame e incremento nas taxas de abortamento (acima de $5 \%$ dos animais em gestação). Alguns animais foram necropsiados e o material coletado (cérebro, fígado, pulmão) e alguns leitões vivos com sinais clínicos foram enviados ao Instituto de Pesquisas Veterinárias Desidério Finamor (IPVDF) onde foi realizado o isolamento do VDA em linhagem celular Madin Darby Bovine Kidney (MDBK), no dia 30.01.2003 (vide artigo subseqüiente, Silva et al. 2005). O foco índice foi imediatamente erradicado, totalizando 2.740 suínos encaminhados a abate sanitário em frigorífico sob Inspeção Federal previamente definido.

Pelo inquérito sorológico foram detectados mais cinco rebanhos com sorologia positiva para o VDA (Fig.2A), também erradicados pela mesma estratégia, totalizando 7.822 animais. A maior parte $(n=4)$ dos rebanhos soropositivos foi infectada pela introdução de animais oriundos do foco índice. Uma granja limítrofe foi infectada provavelmente devido à proximidade $\mathrm{e}$ ausência de isolamento.

\section{Evento 2 (E2)}

Notificado em 02.09.2003, foi inspecionado no mesmo dia por uma equipe do DPA/SAA, que registrou foco e enviou material para necropsia no IPVDF. A granja notificada era considerada UPL, porém mantinha comércio de reprodutores para o sistema integrado, alojando 710 matrizes. Estava localizada em Aratiba, município do norte do RS, limítrofe com Santa Catarina (Fig.1). A granja mantinha leitões de terminação em dependências ociosas, em parte oriundos de outras granjas. Nos 30 dias anteriores à notificação, apresentou animais com encefalite resistente à terapia com antibióticos, com um aumento no número de casos nos últimos dias. As amostras remetidas ao CPVDF confirmaram a etiologia através de isolamento do VDA. Essa granja originou focos secundários pela distribuição de matrizes no mês anterior à confirmação da etiologia. Os focos índice e primário foram depopulados imediatamente (total de 3.370 suínos). Pelo rastreamento das movimentações de suínos e dentro do raio de foco foram detectados outros sete rebanhos que apresentavam animais com sinais clínicos. $\mathrm{O}$ inquérito sorológico detectou

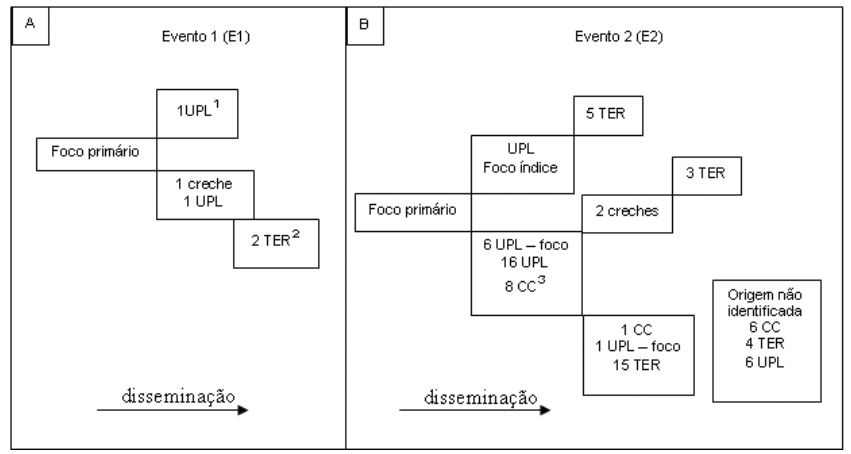

Fig. 2. Disseminação dos focos em E1 (A) e E2 (B) de forma esquemática. A progressão dos retângulos em diagonal representa a disseminação a partir do foco primário, com o número de granjas afetadas. Abreviaturas utilizadas: ${ }^{1} \mathrm{UPL}=$ unidade produtora de leitões; ${ }^{2} \mathrm{TER}=$ terminações (granjas que alojam apenas animais de terminação); ${ }^{3} \mathrm{CC}=$ ciclo completo (granjas que abrigam todas as fases produtivas: cria, recria, terminação). 
Quadro 1. Inquérito epidemiológico e sorológico nas áreas de foco de doença de Aujeszky no Rio Grande do Sul, em janeiro-abril/2003 (E1) e setembro/2003-janeiro/2004 (E2), por função produtiva da granja

\begin{tabular}{|c|c|c|c|c|c|c|c|c|}
\hline \multirow[t]{2}{*}{ Função } & & \multicolumn{3}{|c|}{ Evento 1} & \multicolumn{3}{|c|}{ Evento 2} & \multirow[b]{2}{*}{ Total geral } \\
\hline & & Negativo ${ }^{a}$ & Positivo b & $\overline{\text { Total }}$ & Negativo & Positivo & Total & \\
\hline \multirow[t]{4}{*}{$\mathrm{CC}^{\mathrm{c}}$} & № granjas & 73 & 1 & 74 & 293 & 16 & 309 & 383 \\
\hline & População & 930 & 1 & 931 & 20658 & 1420 & 22078 & 23009 \\
\hline & Granjas coletadas & 26 & 0 & 26 & 273 & 16 & 289 & 315 \\
\hline & População coletada & 351 & 0 & 351 & 1852 & 185 & 2037 & 2388 \\
\hline \multirow[t]{4}{*}{$\mathrm{C}$} & № granjas & 3 & 1 & 4 & 5 & 2 & 7 & 11 \\
\hline & População & 4668 & 2899 & 7567 & 4400 & 2890 & 7290 & 14857 \\
\hline & Granjas coletadas & 3 & 0 & 3 & 5 & 2 & 7 & 10 \\
\hline & População coletada & 120 & 0 & 120 & 177 & 111 & 288 & 308 \\
\hline \multirow[t]{4}{*}{ MUL } & № granjas & 0 & 0 & 0 & 5 & 0 & 5 & 5 \\
\hline & População & 0 & 0 & 0 & 14115 & 0 & 14115 & 14115 \\
\hline & Granjas coletadas & 0 & 0 & 0 & 5 & 0 & 5 & 5 \\
\hline & População coletada & 0 & 0 & 0 & 309 & 0 & 309 & 309 \\
\hline \multirow[t]{4}{*}{ TER } & № granjas & 34 & 2 & 36 & 179 & 27 & 206 & 242 \\
\hline & População & 11720 & 920 & 12640 & 23415 & 12354 & 35769 & 48409 \\
\hline & Granjas coletadas & 28 & 1 & 29 & 148 & 27 & 175 & 204 \\
\hline & População coletada & 640 & 40 & 680 & 1907 & 1019 & 2926 & 3606 \\
\hline \multirow[t]{4}{*}{ UPL } & № granjas & 30 & 2 & 32 & 71 & 32 & 103 & 135 \\
\hline & População & 17259 & 4002 & 21261 & 18285 & 11779 & 30064 & 51325 \\
\hline & Granjas coletadas & 29 & 2 & 31 & 68 & 30 & 98 & 129 \\
\hline & População coletada & 1383 & 294 & 1677 & 1670 & 934 & 2604 & 3281 \\
\hline \multirow[t]{4}{*}{ Total } & Granjas & 140 & 6 & 146 & 553 & 76 & 630 & 776 \\
\hline & População & 34577 & 7822 & 42399 & 80873 & 28443 & 109316 & 151715 \\
\hline & Granjas coletadas & 86 & 3 & 178 & 499 & 75 & 574 & 752 \\
\hline & População coletada & 2494 & 334 & 2828 & 5915 & 2249 & 8164 & 10992 \\
\hline
\end{tabular}

Fonte: DFDSA/DPA/SAA/RS

${ }^{a}$ Granjas rastreadas que não tiveram animais enfermos ou sorologicamente positivos;

b Granjas rastreadas onde animais apresentaram sinais clínicos ou sorologia positiva;

${ }^{\mathrm{c}} \mathrm{CC}=$ ciclo completo, $\mathrm{C}=$ creche, $\mathrm{MUL}=$ multiplicadora (granjas de matrizes destinadas às UPL), TER $=$ terminação, UPL

$=$ unidade produtora de leitões.

outros 69 rebanhos com sorologia positiva. Apenas 16 granjas com animais sorologicamente positivos não tiveram confirmadas a origem do agente, apesar de inseridas dentro de áreas de foco (Fig.2B). Todas as rebanhos com animais soropositivos foram erradicadas, direcionando os animais alojados para o abate sanitário.

O Quadro 1 apresenta um resumo dos dados referentes aos dois eventos. $\mathrm{O}$ inquérito epidemiológico abrangeu todas as granjas dos raios de foco determinados, além das que forneceram ou receberam animais de granjas com DA nos 90 dias anteriores à confirmação da suspeita. No momento da coleta de amostras para provas sorológicas foram excluídas algumas granjas, principalmente terminações - parte da estratégia de contenção dos focos consistiu em esvaziar terminações com animais prontos para o abate sem histórico clínico compatível com DAque já estavam vazias no momento da coleta.

No E1 o foco índice foi uma UPL, cuja finalidade era abastecer granjas vizinhas com leitões de recria ou terminação, atingindo assim um pequeno número de granjas em um raio limitado de dispersão e que mantinham relações comerciais com o estabelecimento (Fig.2A). Não houve disseminação a partir desses focos primários, provavelmente porque os fluxos principais de animais a partir dessas granjas eram direcionados ao abate. Já em E2 o foco índice tinha como função o fornecimento de matrizes para outros integrados, com distribuição de matrizes para 60 granjas nos 90 dias anteriores à notificação. Essa movimentação resultou na contaminação de 30 granjas a partir do foco índice, 19 a partir de focos primários e 21 por contato direto entre granjas dentro da área de foco (Fig.2B). É provável que o VDA já tivesse sido introduzido na granja pelo menos 30 dias antes da notificação, pela possibilidade de introdução de animais para terminação vindos de outros rebanhos. Esse fato permitiu que grande número de matrizes destinado a outros rebanhos tivesse contato com o agente, $o$ que determinou incidência predominante da DA dentro do sistema integrado.

\section{DISCUSSÃO}

O destino dos animais produzidos no foco índice determinou a área de disseminação do agente, fato visível ao comparar as áreas atingidas em E1 e E2, onde a ocorrência em granja que comercializava reprodutores teve uma maior disseminação. Situação epidemiológica semelhante foi observada em granjas de reprodutores soropositivos para DA em Santa Catarina (Mores et al. 2003). Em E1 o destino dos animais comercializados a partir do foco índice era predominantemente para terminações, ponto final da cadeia produtiva, evitando a dispersão de animais infectados e reduzindo a disseminação do agente.

Nos dois surtos foi possível o rastreamento das movimentações de animais vivos que deram origem aos focos. Não foi possível, entretanto, comprovar o modo como foi introduzido o 
vírus nas áreas afetadas. No E2, a fonte de infecção não pode ser identificada em algumas granjas $(n=16)$ (Fig.1B). A impossibilidade de se atribuir uma origem à infecção detectada em todas as granjas afetadas constitui-se em um fator preocupante na epidemiologia do VDA (Austin et al. 1993, Bech-Nielsen et al. 1995). Eventualmente é citada a disseminação por aerossóis, hipótese comprovada em dados circunstanciais, atribuídas a um somatório de condições ideais (Christensen et al. 1993). A transmissão experimental por essa via foi comprovada, porém com baixa eficiência e com a participação de outros fatores predisponentes, tais como concentração de animais e ventilação forçada (Gillespie et al. 1996, Gillespie et al. 2000). O número de animais do rebanho não é decisivo para a disseminação dentro da granja (Bouma et al. 1995), porém a densidade de rebanhos numa determinada área geográfica e o relacionamento entre granjas pode influenciar nos padrões de disseminação de DA (Bech-Nielsen et al. 1995).

O contato direto entre animais ainda prevalece como a via principal de disseminação do VDA (Kluge et al. 1999, Sobestiansky et al. 1999). No presente surto, o contato provavelmente foi a via de disseminação predominante, comprovado pela incidência da doença em rebanhos que receberam reprodutores do foco índice (E2), ou pelo trânsito de animais vivos em transações comerciais. A participação de animais silvestres envolvidas na transmissão do VDA pode ser descartada pela inexistência de espécies potencialmente relacionadas à DA nas áreas afetadas. No entanto, a possibilidade de transmissão por vetores mecânicos, geralmente de pouca importância na epidemiologia da doença, não pode ser totalmente descartada (Kluge et al. 1999).

A deficiência na aplicação de medidas de manejo em saúde animal nas granjas afetadas foi preocupante nos dois eventos. A inexistência de estrutura de quarentena nas UPL, ou mesmo nas granjas de reprodução (E2), além da falta de especialização dentro do sistema de integração (por exemplo: UPL e animais terminação na mesma instalação) podem comprometer a cadeia local de produção (Sobestiansky 2002). A comercialização de reprodutores sem as condições sanitárias determinadas no Plano Nacional de Sanidade Suína (PNSS) contraria as normas sanitárias estipuladas em portaria (MAPA 2002). Esses fatos denunciam a precariedade na aplicação de estratégias simples visando a preservação da saúde animal, facilitando a introdução de agentes patogênicos.

A contaminação dos focos índice provavelmente ocorreu através da introdução de animais provenientes de focos ativos de DA, sendo a origem mais provável Santa Catarina. Esta hipótese está alicerçada na situação endêmica que persiste desde a década de 1980 naquele Estado, com tendência de progressão no número de granjas afetadas (Rowe \& Romero 1986, Mores \& Zanella 2003). A principal razão do RS estar livre da DA até a ocorrência dos eventos em 2003 provavelmente seja a predominância de trânsito de suínos vivos no sentido sul-norte (Roehe et al. 1996). A inversão desse fluxo, motivada por fatores econômico-financeiros momentâneos, pode ter contribuído para a introdução de animais infectados no RS. É possível também que a introdução de animais tenha se constituído em um evento esporádico, sem associação com o fluxo comercial de animais. Apesar dos resultados da sorologia apontarem uma disseminação abrangente na área de foco, com esses dados é impossível afirmar que já havia atividade viral anterior na área. É notório, no entanto, que não havia atividade viral pelo menos até 1996, segundo reportado previamente (Roehe et al. 1996).

Baseado no Código Zoosanitário Internacional, o RS era enquadrado na situação de "provisoriamente livre". Para a obtenção do status de "livre" seria necessário implantar um programa específico de controle e monitoramento da DA adaptado à situação epidemiológica (OIE 2003). Somando-se à inexistência de notificações de DA na região, optou-se pela aplicação da alternativa mais eficiente e rápida quanto à eliminação de risco de disseminação do VDA através de depopulação total, buscando a restauração do status sanitário anteriormente vigente (Morrison 1994).

Outra alternativa seria a introdução do uso de vacinas em um esquema de emergência, semelhante ao realizado em regiões de ocorrência endêmica, como no caso do Estado de Santa Catarina (Mores \& Zanella 2003). Entretanto, a vacinação não impede completamente a disseminação do VDA, podendo facilitar a dispersão de animais portadores (Van Oirschot et al. 1990, Kimman 1994).

A opção pelo uso da estratégia de depopulação total das granjas contaminadas pelo VDA se mostrou eficiente, permitindo o retorno ao status sanitário anterior à ocorrência dos focos. No entanto, permanece o risco de novas introduções do agente pela situação de endemia em Santa Catarina, apesar dos progressos do programa de erradicação naquele Estado. É aconselhável a manutenção de estratégias de controle ao longo da fronteira com o objetivo de reduzir ou impedir o trânsito, principalmente de suínos não-certificados, entre os dois estados. Concomitantemente, as empresas integradoras da região poderiam adotar programas de biosseguridade visando proteger os rebanhos de seus integrados da introdução do VDA e de outros agentes patogênicos. Seria adequado discutir a adoção de estratégias ou programas oficiais de controle e erradicação da DA, tendo em vista prevenir a disseminação da enfermidade, o que causaria prejuízos extensos à exploração de suínos no Brasil.

\section{REFERÊNCIAS}

Austin C.C., Weigel R.M., Hungerford L.L. \& Biehl L.G.1993. Factors affecting the risk of infection with pseudorabies virus in Illinois swine herd. Prev. Vet. Med. 17:161-173.

Bauer A.G. 1955. Primeira constatação do mal de Aujeszky no Rio Grande do Sul. Arq. IPVDF, Porto Alegre, 1:15-16.

Bech-Nielsen S., Miller G.Y., Bowman G.L., Burkholder R.H., Dodaro S.J. \& Palte W.J. 1995. Risk factors identified as source of new infections (area spread) with pseudorabies (Aujeszky's disease) virus in 50 swine herds in a contiguous geographic area of Ohio. Prev. Vet. Med. 23:53-64.

Bouma A., de Jong M.C.M. \& Kimman T.G. 1995. Transmission of pseudorabies virus within pig population is independent of the size of the population. Prev. Vet. Med. 23:163-172.

Christensen L.S., Mortensen S., Botner A., Strandbygaard B.S., Ronshold 1., Henriksen C.A. \& Andersen J.B. 1993. Further evidence of long distance airborne transmission of Aujeszky's disease (Pseudorabies) virus. Vet. Rec. 132:317-321.

Crandell R.A., Mesfin G.M \& Mock R.E. 1982. Horizontal transmission of pseudorabies virus in cattle. Am. J. Vet. Res. 43(2):326-328. 
Dohon I.R., Martin W. \& Strhyhn H. 2003. Veterinary Epidemiologic Research. 1st ed. AVC, Charlottetown, p.54-64.

Gillespie R.R., Hill M.A. \& Kanitz C.L. 1996. Infection of pigs by aerosols of Aujeszky's disease virus and their shedding of the virus. Res. Vet. Sci. 60:228-233.

Gillespie R.R., Hill M.A., Kanitz C.L., Knox K.E., Clark L.K. \& Robinson J.P. 2000. Infection of pigs by Aujeszky's disease virus via the breath of intranasally inoculated pigs. Res. Vet. Sci. 68:217-222.

Kimman T.G. 1994. Immunological protection against pseudorabies virus. Annals OIE Symposium Bangkok. OIE, Paris, p.11-22.

Kluge J.P., Beran G.W., Hill H.T. \& Platt K.B. 1999. Pseudorabies (Aujeszky's Disease), p.233-146. In: Straw B.E, D’Allaire S., Mengeling W.L., Taylor D.J. (ed.) Diseases of Swine. Iowa State University Press, Ames.

MAPA (Ministério da Agricultura, Pecuária e Abastecimento) 1985. Instrução Normativa DIPROD 001/85. http://www.agricultura.gov.br/das/dda/ pdf/legislacão_pnss_1.pdf.

MAPA (Ministério da Agricultura, Pecuária e Abastecimento). 2002. Instrução Normativa SDA 19/02, feb./15. Diário Oficial da União no. 41, Seção 1 .

Marques J.L.L. \& Romero C.H. 1986. A vigilância sorológica para o vírus da doença de Aujeszky em suínos no estado de Santa Catarina. Pesq. Vet. Bras. 6(4):117-119.

Miller G.Y., Tsai J.-S. \& Forster L. 1996. Benefit-cost analysis of the national pseudorabies eradication program. J. Am. Vet. Med. Assoc. 208(2):208213.

Moynagh J. 1997. Aujeszky's disease and the European Community. Vet. Microbiol. 55: 159-166.

Morés N. \& Zanella J.C. 2003. Programa de erradicação da doença de Aujeszky no Estado de Santa Catarina. Anais XI Congr. Veterinários Especialistas em Suínos. UFGO, Goiânia, p.126-131.

Morés N., Amaral A.L., Ventura L., Ciacci-Zanella J.R., Mori A., Dambrós R.M.F., Provenzano G. \& Bisolo E. 2003. Relato epidemiológico do comércio de reprodutores suínos de reposição com sorologia positiva para o vírus da Doença de Aujeszky. Anais XI Congr.Veterinários Especialistas em Suínos. UFGO, Goiânia, p.113-114.

Morrison R.B. 1994. Elimination of Aujeszky's Disease virus from swine herds. Annals OIE Symposium Bangkok. OIE, Paris, p.45-53.

Müller T., Bätza H.-J., Schlüter H., Conraths FJ. \& Mettenleiter T.C. 2003. Eradication of Aujeszky's disease in Germany. J. Vet. Med. B Infect. Dis. Vet. Public Hlth 50:207-213.

OIE (Organização Internacional de Epizootias) 2000. Manual of Standards Diagnostic Tests and Vaccines. http://www.oie.int/eng/normes/mmanual/ a_00039.htm.

OIE (Organização Internacional de Epizootias) 2003. Terrestrial Animal Health Code. http://www.oie.int/eng/normes/mcode/A_00047.htm.
OIE (Organização Internacional de Epizootias) 2004. Handistatus. http:// www.oie.int/handistatus.

Roizman B \& Pellet P.E. 2001. The Family Herpesviridae: a brief introduction, p.2381-2397. In: Knipe D.M., Howlet P.M. (ed.) Virology. Lippincott Williams \& Wilson, Philadelphia.

Rodrigues C.A., Gardner I.A. \& Carpenter T.E. 1990. Financial analysis of pseudorabies control and eradication in swine. J. Am. Vet. Med. Assoc. 197(10):1316-1323.

Roehe, P.M., Souza R., Salvo E.O., Martins R.M., Oliveira L.G., Hoffmann V.L., Rosa J.C.A. \& Trevisol I.M. 1996. Ausência de anticorpos contra o vírus da doença de Aujeszky em suínos no Estado do Rio Grande do Sul. Arq. Bras. Med. Vet. Zootec. 48(3):363-367.

Romero C.A., Meade P.N., Homer B.L., Shultz J.E. \& Lollis G. 2003. Potential sites of virus latency associated with indigenous pseudorabies viruses in feral swine. J. Wildl. Dis. 39(3):567-575.

Rowe C.A. \& Romero C.A. 1986. Isolamento e identificação do vírus da Doença de Aujeszky de surtos em suínos no estado de Santa Catarina. Pesq. Vet. Bras. 6(3):99-103.

Silva A.D., Spilki F.R., Braga A.C., Franco A.C., Rijsewijk F.A.M., Stepan A.L.S., Rosa J., Machado C.H. \& Roehe P.M. 2003. Virological findings from the recent outbreak of Aujeszky's disease in Rio Grande do Sul. Virus Rev. Res. 8(1):133-134.

Silva A.D., Sortica V.A., Braga A. C., Spilki F.R., Franco A.C., Esteves P.A., Rijsewijk F.A.M., Rosa J.C.A., Batista H.B.H. \& Roehe, P. M. 2005. Caracterização antigênica e molecular de vírus da doença de Aujeszky isolados no Estado do Rio Grande do Sul. Pesq.Vet.Bras. 25(1):21-24.

Sobestiansky J., Barcellos D.E.S.N., Morés N., Oliveira S.J., Carvalho L.F.O.S., Moreno A.M. \& Roehe P.M. 1999. Clínica e Patologia Suína. Edição independente. $2^{\underline{a}}$ ed. Goiânia. 464p.

Sobestiansky, J. 2002. Sistema Intensivo de Produção de Suínos - Programa de Biossegurança. O Autor, Goiânia. 108p.

Vannier P., Vedeau F. \& Allemeersch C. 1997. Eradication and control programmes against Aujeszky's disease (pseudorabies) in France. Vet. Microbiol. 55:167-173.

Van Oirschot J.T., Gielkens A.L.J., Moormann R.J.M. \& Berns A.J.M. 1990. Marker vaccines, virus-specific antibody assays and the control of Aujeszky's disease. Vet. Microbiol. 23:85-101.

Van Oirschot J.T., Kaashoek M.J., Rijsewijk F.A.M. \& Stegeman J.A. 1996. The use of marker vaccines in eradication of herpesviruses. J. Biotechnol. 44:75-81

Vidor T. 1988. Doença de Aujeszky etiopatogenia e controle. Hora Vet., Porto Alegre, 8(43):47-52.

Willemberg P., Leontides L., Ewald C., Mortensen S., McInerney J.P., Howe K.S. \& Kooij D. 1996. Effect of vaccination against Aujeszky's disease compared with test and slaughter program: epidemiological and economical evaluation. Acta Vet. Scand. (Suppl.) 90:25-51. 
